\title{
THE REVIVAL OF EMOTIONAL MEMORIES AND ITS THERAPEUTIC VALUE. (II) ${ }^{1}$
}

\section{By CHARLES S. MYERS.}

I sUPpose I was the first (in a paper written by me in France during the autumn of 1914) to lay stress on the excellent results of immediate attention to the amnesia in cases of 'shell-shock.' I began then to employ this principle of treatment not only for the cure of functional bodily disorders, but also and especially in order to alleviate the depression, the fear of insanity and the other mental disturbances associated with the amnesic state--in other words to bring the patient completely to 'himself' again. Since that time I always tried to encourage the adoption of this line of treatment in the various neurological hospitals with which I became connected. In the case of Dr Brown's wards, such encouragement was superfluous, for his previous psychological training had at once shown him the importance of dealing instantly with the amnesic symptoms of his patients. He and I, however, came finally to take up somewhat different points of view in regard to this treatment. Owing, perhaps, to his more frequent use of hypnosis in recovering lost memories, he was led to think that the revival of emotional expression was the most important element, while my own experience, in recovering memories both in the waking and in the hypnotic state, was that the acting out of the emotional experience was of relatively little consequence, but that what was of importance was the revival of the unpleasant memory of the scene, i.e. the revival of the dissociated affective and cognitive experience. Indeed I used to discourage undue prominence of the emotional response during the recollection in hypnosis of what had been forgotten, because I always used hypnosis at so slight a stage that my patients would complain of headache and wake up rather than allow their emotion full play. I therefore made a practice of using such persuasions as-_."Now when I put my hand on your forehead, you will be back in the trenches again, but you will not be unduly afraid, you will be able to live through it all again calmly and to tell me all that happened to you." Unfortunately no opportunity occurred for a satisfactory comparison of these two methods of treatment in France, although I endeavoured more than once to get such an inquiry started. But I never had reason to suppose that my principle of treatment was in any way less effective than Dr Brown's. I could quote numerous instances of

2 A contribution to a discussion at a meeting of the Medical Section of the British Psychologioal Society on February 18, 1920. 
recovery in favour of my view that it is the recall of the repressed scene, not the 'working out' of the 'bottled up emotional energy' (to use Dr Brown's terminology), which is responsible for the cure.

I had many opportunities, of course, during my duties in France, of seeing Dr Brown at actual work on his own lines. And I should like to take this opportunity of stating that his most uncompromising opponent could not point to a hospital where the functional nervous cases presented a more satisfactory physical appearance or where sa many were returned direct to duty and fewer were sent down to the base hospitals. Now both in his patients and occasionally in my own, I have seen the emotions of fear, terror and even anger in full force during the return of these memories under hypnosis. But I seldom found myself in agreement with Dr Brown, that these were emotions which had not been previously felt and displayed in the trenches. In some cases, I am ready to admit, the patient had probably exercised stronger control over their expression when in the firing-line. But generally I believe that what we obtained in such cases during hypnotic revival was a literal re-enactment, a living through again, of the scenes and experiences of actual warfare accompanied by their original excitement.

Having thus stated the difference in our point of view, I pass on to raise questions for discussion. The first question for discussion seems to me this: Do emotions become repressed, and if so in what direction does the repression act? Dr Brown will be the first to agree that the emotion must be distinguished from its expression. In cortico-thalamic lesions, the most striking effect of the release of the thalamus from cortical inhibition is the exaggerated affective experience, the increase of pleasure and discomfort on the side affected. But an emotional increase limited to one side of the body is clearly inconceivable, although increased unilateral response to emotional excitement has been observed in such cases by Head and Holmes. It may be doubted, however, whether increased emotional response generally means increased emotional feeling. And it is, I gather, the control exercised oyer emotional expression rather than the control exercised over emotional feeling on which Dr Brown bases the rationale of abreaction. For him the 'bottling up' of emotional expression is the prime cause of dissociation. To this I shall return immediately.

Let us next turn to what Freud has termed the psycho-pathology of every-day life. What is it we are prone to forget? Is it always or primarily the emotional? No, it is the unpleasant which becomes repressed. Turn again, conversely, to the every-day involuntary persistent return of bygone experiences to consciousness. It is the extraordinarily pleasant 
or unpleasant scenes that insist on obtruding themselves, not the emotional ones, $q u \hat{a}$ emotional. An emotion does not in every-day life return apart from association with some content; once aroused, it may, of course, persist as a mood.

For these reasons I submit that there is an inherent probability that the cause of functional amnesia is not repression of the emotional, but repression of the affective component. The scene is too intolerably unpleasant to be revived; and the resistance to recall is, ceteris paribus, a measure of the unpleasantness.

A careful distinction must be made between dissociation, as a process of disintegration, and repression, as a process of inhibition. The two often concur, but are not therefore to be confused or to be regarded as identical. Thus, dissociation can hardly occur without the subsequent inhibition of what has become dissociated-any more than association can hardly occur without facilitation of what has become associated. The common view is to regard all dissociation as the consequence of conflict and attempted repression. For Freud the conflict occurs between wishes, for Dr Brown between emotions. But I do not think that in cases of 'shell-shock' conflict and attempted repression necessarily precede dissociation. Efforts at repression certainly weaken previous selfcontrol, produce anxiety and in this way conduce to dissociation. But in many, if not in most, cases of shell-shock, I think the essential pathological process consists in a dissociation affecting the entire personality owing to sudden emotional shock. The soldier is no longer 'himself'; and with the return of his apparently normal 'self,' repression occurs and that repression is primarily confined to the affective and cognitive sides, and only to the emotional so far as it is associated therewith. It is the affective-cognitive aspect which receives censure and is repressed. The memory of the actual scene hardly ever escapes from its repression. Not so the emotion. It is merely dissociated and may repeatedly disturb the waking and sleeping life of the patient in many well-known ways.

These are the principal lines of thought that Dr Brown's views have suggested to me. They incline me to the conclusion that the value of 'autognosis,' to use his expressive term, consists in relieving the affective-cognitive repression and in redintegrating the various dissociated components, not, as Dr Brown maintains, in securing emotional revival. I am disposed to doubt whether attempted control over emotional expression ever leads directly to functional nervous disorder, and whether dissociation of emotion or emotional expression ever occurs, save indirectly through dissociation and repression of the cognitive and affective experiences linked thereto. 